\title{
SOBRE TRADUTIBILIDADE E INTRADUTIBILIDADE EM WALTER BENJAMIN ${ }^{1}$
}

\author{
Burghard Baltrusch \\ Universidade de Vigo \\ Vigo, Galiza, Espanha
}

\begin{abstract}
Resumo: O Vocabulaire européen des philosophies. Dictionnaire des intraduisibles define a noção do intraduzível como "aquilo que não cessamos de (não) traduzir". Um exemplo paradigmático de um texto continuamente traduzido desde a segunda metade do século XX é o ensaio fundacional da teoria da tradução moderna, "A tarefa do tradutor" de Walter Benjamin. A partir de um breve panorama de 27 traduções ibero-românicas, italianas, inglesas e francesas, desde 1962 e com especial ênfase no caso brasileiro, este estudo pretende oferecer uma reflexão em torno às questões de tradutibilidade e intradutibilidade em Walter Benjamin. Analizar-se-ão algumas das passagens mais complexas da Tarefa para ilustrar como a teoria benjaminiana tenta resignificar a ideia do original a partir da noção de um "continuum de transformações”. Argumentar-se-á, também, que o conceito da "pura língua" pode ser entendido como um essencialismo estratégico, uma ferramenta discursiva para negociar entre o traduzível e o intraduzível.
\end{abstract}

Palavras-chave: Walter Benjamin; Tradutibilidade; Intradutibilidade; "Língua pura"; Tradução e Hermenêutica

${ }^{1}$ Este estudo forma parte do projeto de pesquisa "Poesía contemporánea en el espacio público: intervención, transferencia y performatividad" (POESPUBLIC, FFI2012-33589, 2012-2016, Ministerio de Economía y Competitividad del Gobierno de España) e do Programa Estratégico UID/ELT/00500/2013 da FCT (Portugal). 


\title{
ON TRANSLATABILITY AND INTRANSLATABILITY IN WALTER BENJAMIN
}

\begin{abstract}
The Vocabulaire européen des philosophies. Dictionnaire des intraduisibles defines intranslatability as "what one does not cease to (not) translate". A paradigmatic example of a text continuously translated since the second half of the twentieth century, is the foundational essay of modern translation theory, "The translator's task" by Walter Benjamin. Starting with a brief overview of 27 Ibero-Romance, Italian, English and French translations since 1962, with special emphasis on the Brazilian case, this paper will offer a reflection on the issues of translatability and intranslatability in Walter Benjamin. Some of "The tranlator's Task"'s more complex passages will be analyzed to illustrate how Benjamin's theory attempts to reframe the idea of the original through the notion of translation as a "continuum of transformations." It will be argued that the concept of "pure language" can be understood as a strategic essentialism, a discursive tool for negotiating between the translatable and the untranslatable.
\end{abstract}

Keywords: Walter Benjamin; Translatability; Intranslatability; "Pure language"; Translation and hermeneutics

O pensamento de Walter Benjamin sobre a tradutibilidade e a intradutibilidade foi desenvolvido, principalmente, nos seus ensaios Über die Sprache überhaupt und über die Sprache des Menschen (1916) e Die Aufgabe des Übersetzers (1923)². A partir destes textos, o presente estudo propõe uma síntese e atualização da dicotomia do traduzível e do intraduzível através de uma reinterpretação do conceito benjaminiano da "pura língua" e do que se considera ser o horizonte teológico do seu pensamento tradutológico.

2 "Sobre a linguagem em geral e sobre a linguagem humana" e "A tarefa-abandono de quem traduz". 


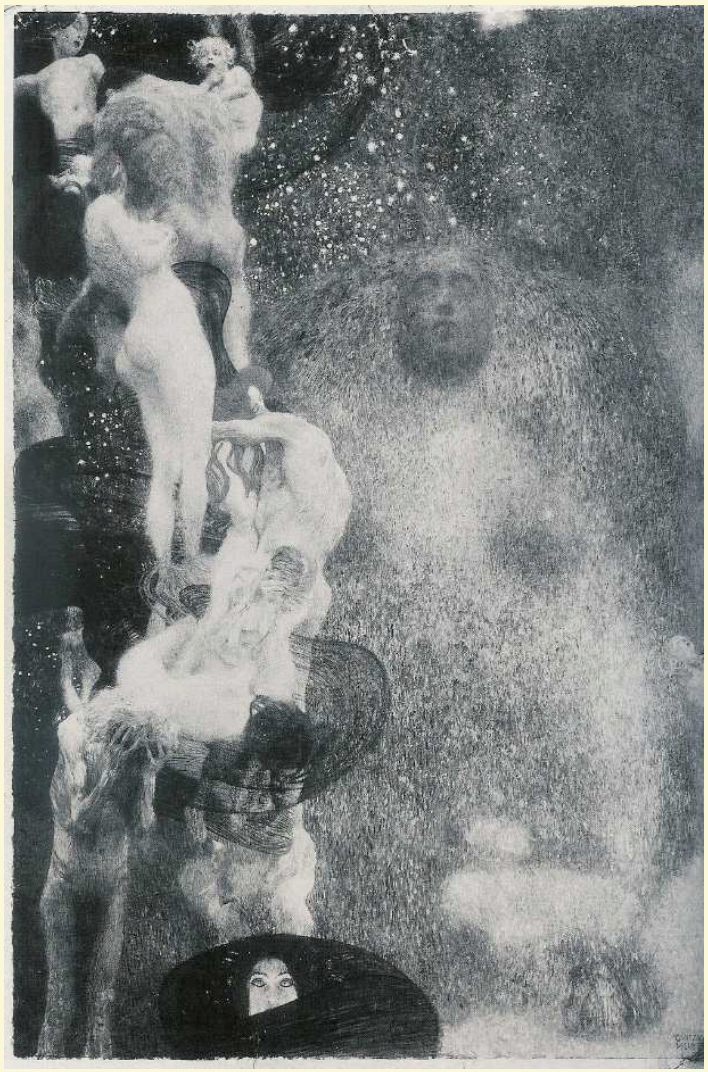

Fig. 1: Philosophy, Medicine and Jurisprudence, Klimt. Fonte: Klimt Museu.

Para introduzir estas reflexões gostaria de evocar, a modo de comparação, uma imagem que considero útil para exemplificar a íntima relação entre hermenêutica e tradução, na qual se inscreve a filosofia do pensador alemão.

Trata-se de uma fotografia em preto e branco do desaparecido quadro "Filosofia" de Gustav Klimt (cfr. FLIEDL, 1989, p. 80). Em 1894, o pintor austríaco ficou encarregado de decorar o teto da grande sala da Universidade de Viena e, até 1900, surgem os quadros "Filosofia", "Medicina" e "Jurisprudência", depois fo- 
ram rejeitados por uma parte da elite cultural austríaca por não se aterem ao padrão artístico do momento. Apesar disso, uma das primeiras versões de "Filosofia" recebeu a medalha de ouro na Exposição Mundial em Paris (1900). Segundo o artista, as figuras da esquerda seriam alegorias do princípio da vida, da fruição e da decadência. Abaixo, surge a Filosofia como uma cara iluminada a sair da escuridão, a representar o conhecimento, base de um fluir de figuras que simboliza o devir humano. Na direita, há uma personificação do enigma da vida e do mundo, em forma de esfinge. Os seus olhos fechados parecem indicar que o enigma já está solucionado, uma vez que o ciclo da vida nasce da cabeça da sabedoria, enquanto os olhos, igualmente fechados, das figuras humanas sugerem que estas ainda se encontram num estado de inconsciência ou incompreensão. A ideia subjacente parece ser a de que o verdadeiro conhecimento parte da fusão entre o racional e a intuição, o que em Klimt era, possivelmente, uma influência teósofica. Em todo o caso, foi esta suposta relativização do racionalismo que originou os protestos do mundo académico da Viena do fin-de-siècle (FELLINGER et al., 2012, p. 119). O que está claro é que o quadro não representa nem um princípio nem um fim inequívocos, antes, convida a reflexionar sobre a relação entre a ideia e a prática de uma filosofia que aparece libertada dos preceitos de imparcialidade e objetividade.

Em certa medida, esta abertura de registro para um olhar antipositivista sobre a experiência e a memória seria comparável à ideia benjaminiana da origem e da receção da tradução como um devir não historicista das línguas e das culturas. Também em Walter Benjamin temos esta rejeição da suposta imparcialidade de um conhecimento sempre condicionado pelo embate de interesses e ideologias. A "Filosofia" de Klimt oferece-se, neste sentido, como um exemplo de tradução intersemiótica entre filosofia e arte, entre pensamento e imagem e, finalmente, entre filosofia e a tradução em geral.

Repare-se em que optei por dizer traduzir entre, e não para. Com o entre quero destacar a ideia de um terceiro espaço-tempo que se abre entre o elemento de partida e o de chegada, entre o pas- 
sado e o futuro, mas que também os relaciona. É o espaço-tempo da tradução, a decorrer no nosso presente histórico imediato (no qual a observação sempre parte de um presente), embora este, na maioria dos casos, permaneça invisível, seja em relação ao sujeito ou ao próprio processo. Neste caso, dá-se a coincidência de que o quadro original já não existe: $\mathrm{O}$ projeto da sua instalação na Universidade de Viena nunca chegou a ser realizado e só se produziu um modelo, do qual se tiraram algumas fotografias em preto e branco. São, hoje em dia, os únicos documentos das obras que foram destruídas por um incêndio provocado na sequência da retirada das SS da Áustria em 1945.

Poderíamos tomar estas circunstâncias - tanto acidentais, ideológicas como também intencionalmente violentas - como uma ilustração paradigmática da condição de trânsito ao que está sujeito o que habitualmente denominamos "o original". Todo o suposto original acaba por ser transformado ao longo dos tempos por múltiplos processos de receção, neste caso concreto, pela perda física da pintura, mas também pela fotografia e os diferentes condicionamentos da sua reprodutibilidade técnica. Ficou em questão aquela proximidade da obra, da qual falava Heidegger. O original desvaneceu perante a subjetividade do sujeito recetor e perdeu a sua aura perante uma reprodutibilidade que, ironicamente, o salvou do esquecimento, embora seja somente um mero indício da exuberância visual que provavelmente caraterizara o original no seu momento: Só nos resta uma tradução da ontologia do original como interpretação temporal, uma ideia fugaz do acontecimento artístico que algum dia realmente teve lugar.

A história desta imagem também nos convida a pensar a criação artística como tradução, como um movimento de transposições contínuas ou, nas palavras do próprio Benjamin, como um "continuum de transformações" (1916, p. 261). De certa forma, a experiência deste "continuum" funciona como uma dialética de mudança e estabilidade, um processo alostático como se diria em medicina (cfr. BALTRUSCH, 2010), ou uma dinâmica de distanciamento e aproximação. Contudo, a dimensão poética deste "con- 
tinuum" também nos fala de uma experiência que acaba por se desvincular do seu objeto e por questionar os condicionamentos do próprio conhecimento ( $c f r$. BADIOU, 2004, p. 238). Esta perspetiva poética sobre a tradução inclui certa noção de crítica e resistência à conceitualização essencialista da linguagem, dos discursos e das imagens. Em última instância, também invalida a demanda de objetividade na filosofia tradicional, ou de que uma afirmação ontológica necessita, forçosamente, de apreender um objeto.

É precisamente a dificuldade de apreender e compreender Die Aufgabe des Übersetzers de Walter Benjamin na própria língua de partida que já nos sugere certa noção de intradutibilidade. No seu alemão novecentista e idiossincrásico, numa prosa ao mesmo tempo filosoficamente profunda e poética, o escritor judeu-alemão desenvolveu uma argumentação teórica ambiciosa e de um incomensurável impacto internacional até aos nossos dias, com uma capacidade de influência que só esteve ao alcance de poucos pensadores e pensadoras modernistas. Publicado em 1923, neste prólogo de uma tradução para o alemão dos Tableaux parisiens de Baudelaire, confluem as experiências do Benjamin tradutor das Fleurs $d u$ mal e de À la recherche du temps perdu de Marcel Proust, mas também a sua vivência da arquitetura e da vida urbana parisiense do seu tempo, entre muitos outros aspetos.

$\mathrm{Na}$ "Tarefa” e em "Sobre a linguagem", Benjamin desenvolve a mais influente teoria hermenêutica da tradução do século XX e reelabora temas já tratados no seu estudo sobre $O$ conceito da crítica da arte no romantismo alemão (1919). Lembremos que o Romantismo alemão já tinha esboçado uma proto-teoria tradutológica a partir da utopia de uma poesia universal progressiva (Schlegel). Benjamin vai mais além e desenvolve a ideia de existirem "tantas traduções [do real] como línguas" (1916, p. 69), precedidas de uma "língua das coisas", de um substrato que, real ou supostamente, existe fora da condição humana. Seria isto algo como um original anamnético que, constantemente, aspiramos a traduzir: "É a tradução da língua das coisas para a língua dos seres humanos" (1916, p. 41). 
A ideia de a própria língua ser uma tradução - entre coisas, ideias e palavras - provém de Aristóteles e reaparece no Renascimento na metáfora do mundo como texto legível e decifrável. O Romantismo iria ampliar esta metáfora com a tese da filosofia como um processo de tradução, quando Novalis afirma que a filosofia, na sua tentativa de conferir sentido, traduz o mundo real para o mundo das ideias e vice-versa ${ }^{3}$. Já no século XX, a hermenêutica, uma disciplina que surge precisamente das dificuldades observadas nos processos de tradução, chega a definir a própria compreensão do sentido como uma dinâmica tradutiva, na que as diferenças entre o trabalho de recriação do tradutor/a e a tarefa hermenêutica geral não têm caráter qualitativo, mas somente gradual ${ }^{4}$.

Porém, é Benjamin quem acaba por estabelecer a tradutibilidade como condição ou, até, como uma lei da comunicação. A condição de tradutibilidade, também entendida como um espaço de intervenção precede tanto à linguagem, às línguas individuais como também a todos os fenómenos tradutivos produzindo, assim, a noção de um devir linguístico-semiótico. O desejo de regresso a um suposto real ou original permanecerá, assim, uma utopia tão inalcançável como também indispensável, um paradoxo que Benjamin quis expressar através do célebre conceito benjaminiano da "pura língua" (reine Sprache):

Todo o parentesco meta-histórico entre as línguas repousa sobre o facto de, em cada uma delas, se for tomada como um todo, ser designado o mesmo na sua essência; algo que, porém, não pode ser alcançado por nenhuma delas de maneira isolada, mas somente na totalidade das suas intenções a se complementarem reciprocamente: a pura língua. Pois enquanto essas línguas se complementam a si mesmas nas

\footnotetext{
3 "Der Philosoph übersetzt die wirkliche Welt in die Gedankenwelt und umgekehrt, um beiden einen Verstand zu geben" (1929, cap. 5).

4 "Die Nachbildungsaufgabe des Übersetzers ist nicht qualitativ, sondern nur graduell von der allgemeinen hermeneutischen Aufgabe verschieden, die jeder Text stellt." (GADAMER, 1990, p. 391).
} 
suas intenções, excluem-se todos os elementos isolados das línguas estrangeiras - como palavras, frases, inter-relações. Apreender com exatidão essa lei - uma das fundamentais da filosofia da linguagem - significa diferenciar, na intenção, o tido em mente (das Gemeinte) do modo de ter em mente (die Art des Meinens). (1923, p. 14, trad. minha)

Longe de ser um sinonimo de língua universal, a "pura língua" benjaminiana podia ser vista, hoje em dia, como uma forma de essencialismo estratégico (SPIVAK 1987) ${ }^{5}$ para lidar com o que se considera intraduzível. A sua intenção é reduzir a função abstrata ou comunicativa da língua, cujo peso ideológico dificulta a aproximação do real, aquilo que Novalis tinha denominado o "ponto primordial”. A "pura língua" designa também a transversalidade teórica de língua e história, embora também se refira ao devir da língua como fenómeno cultural, um devir tanto ético como estético, que se manifesta na prática continuada da tradução.

Este devir da língua - ou jogo de forças entre poesia, estética e práxis, como se pensava no Romantismo - foi concebido por Benjamin como tendo uma realidade própria. Tratava-se de ver a língua menos como uma representação do real, do que como pro-

\footnotetext{
${ }^{5}$ É sabido que este conceito tem criado uma certa polémica pelo seu uso e abuso no contexto da sociologia, do pós-colonialismo e do feminismo. Não pretendo levar a questão da pura língua para estes âmbitos, nem quero comparar a relação entre o original e as suas traduções com a que existe entre culturas hegemónicas e grupos minoritários. Porém, o conceito tem uma certa aplicabilidade filosófica, e não só para uma tradução que precisa de uma estratégia para se aproximar daqueles elementos que supostamente constituem a base identitária entre si e o original (apesar de se poderem produzir no próprio processo translatício, ou durante a sua recepção, diferenças fundamentais). Sempre haverá momentos nos quais será útil "essencializar" aspectos do original, ainda que seja de forma temporária e utilitarista, para garantir, por um lado, uma proximidade com o texto de partida mas também para se defender, pelo outro, dos efeitos uniformizadores de certas culturas, tradições ou modas. Uma ampliação filosófica da perspectiva de Spivak também pode ser útil para observar a tradução na sua situação historicamente subalterna em relação ao original, quando "its own subalternity in claiming a positive subject-position for the subaltern might be reinscribed as a strategy for our times" (1987, p. 207). A "pura língua", vista como um essencialismo estratégico que condiciona tanto a tradução como também o próprio original, pode, assim, libertar a tradução da hegemonia do sentido do original, o que iria também ao encontro da teoria desenvolvida por Haroldo de Campos ( $c f r$. infra).
} 
dução ou, melhor dito, como uma tradução do mundo e dos seus significados em constante disseminação. Em consequência, talvez seja mais conveniente entender a "pura língua" como uma mera estratégia de orientação da tradutologia e da prática tradutiva ao longo da história, "eximida" de um sentido único e final ${ }^{6}$.

A questão principal daquilo que poderia ser considerado a teoria da tradução de Benjamin, talvez seja a de apreender, a partir de uma perspetiva tradutológica, as noções de temporalidade e de historicidade e, finalmente, a tentativa de libertar a língua do sentido através da tradução. Estas dimensões hermenéutica e epistemológica da tradução não deviam ser subordinadas à filosofia, mas tem de ser considerada como o seu início e a sua indispensável companheira ${ }^{7}$. Também Jacques Derrida localizou a própria origem da filosofia nesta tese da tradutibilidade geral e fê-lo de uma forma que põe em questão qualquer procura ou comunicação de sentido ou de verdade:

\section{[...] la thèse de la philosophie c'est la traductibilité, la tra- ductibilité en ce sens courant, transport d'un sens, d'une va- leur de verité, d'une langue dans une autre, sans dommage}

\footnotetext{
6 "Se essa última essencialidade, que consititui a pura língua mesma, está vinculada apenas ao material verbal e às suas transformações, aglutina-se a ela nos conjuntos de formas o sentido pesado e estranho. Eximi-la desse sentido, fazer do simbolizante o próprio simbolizado, recuperar a pura língua moldada para a evolução da língua, essa é a grandiosa e única faculdade da tradução. Nessa pura língua - que nada mais tem em mente e que nada mais expressa, mas que representa, enquanto palavra inexpressiva e criadora, o tido em mente em todas as línguas - toda comunicação, todo significado e toda intenção chegam finalmente a um estrato, no qual estão destinados a desvanecerem" (IV:1, p. 19, trad. minha).

7 "E justamente a partir desse estrato, a liberdade da tradução ratifica-se em termos de um direito novo e superior. A liberdade da tradução não justifica a sua existência a partir do sentido da comunicação, uma vez que a tarefa da fidelidade consiste precisamente em emancipar-se dele. Antes, a liberdade afirma-se, por causa da pura língua, na própria língua. Remir aquela pura língua, que está presa na estrangeira, na própria língua, liberá-la do cativeiro da obra através da transcriação, essa é a tarefa da tradução.” (IV:1, p. 19, trad. minha). Porém, é preciso ter em conta que, segundo Benjamin, uma descrição do processo e do devir da tradução só oferece a vaga ideia duma 'verdade' (leia-se: 'do real') que, como tal, sempre permanecerá inapreensível. Isto significa que a estratégia epistemológica e sistemática duma tradução crítica consistirá numa imersão no imaginário alheio, quanto mais completa melhor. Assim, a forma textual da tradução converte-se, por extensão, numa forma cultural.
} 
essentiel. [...] l'origine de la philosophie c'est la traduction, la thèse de la traductibilité, et partout où la traduction dans ce sens-là est en échec, ce n'est rien de moins que la philosophie qui se trouve mis en échec. (1982, p. 159-160)

Esta ideia foi claramente inspirada por Benjamin e, de certa forma, também podemos encontrar na complexa receção que Derrida ( $c f r$. 1987) faz da "Tarefa" uma explicação para a necessidade de existirem, hoje em dia, tantas traduções diferentes deste texto e tantos debates sobre as suas variantes. As múltiplas questões em torno da tradutibilidade ou intradutibilidade deste ensaio deram lugar a uma excecional e variadíssima história de receção e tradução ao longo do século XX e que demonstra a sua relevância epocal para a filosofia da tradução moderna.

O início da história das suas traduções situa-se em 1962 com a versão italiana de Renato Solmi, reeditada em 1995, seguida depois de outra de Antonello Sciacchitano, de $2007^{8}$. Nos anos sessenta também começa o processo de tradução ao castelhano, pela mão do escritor argentino Héctor Álvarez Murena, cuja versão de 1967 foi pelo menos três vezes reeditada ${ }^{9}$ e que conta com uma amplíssima receção em todo o âmbito de fala espanhola. Com o tempo, descobriu-se que esta tradução era defectuosa em muitos sentidos, tendo elidido, por exemplo, um paragráfo inteiro do texto original. Embora a versão de Murena continue a ser a versão dominante no mercado editorial em castelhano, surgiram pelo menos outras quatro traduções ao castelhano, qualitativamente superiores em relação à primeira, embora também com grandes diferenças entre si. São as versões de Marcos Hernández e Carlos Marzán (com a colaboração de Marie Luise Hirschberger, de 1993) ${ }^{10}$, Hans Ch-

\footnotetext{
8 "Il compito del traduttore", em aut aut, 334, 2007, 7-20, disponível em <http:// ebookbrowse.com/il-compito-del-traduttore-pdf-d32880649> (acesso: 12/03/2017).

9 "La tarea del traductor", em Walter Benjamin: Ensayos Escogidos. Buenos Aires: Ediciones Sur 1967; Walter Benjamin: Angelus Novus. Barcelona: Edhasa 1971, 127-14 e em Miguel Ángel Vega (ed.): Textos clásicos de teoría de la traducción. Madrid: Editorial Cátedra, 1994, p. 285-298.

10 "La tarea del traductor", em Laguna. Revista de filosofía, 2, 1993-1994, 153-164.
} 
ristian Hagedorn (1996) ${ }^{11}$, Pilar Estelrich (1996, com uma versão revisada, inédita, de 2011) ${ }^{1211}$ e a de Jorge Navarro Pérez (2010) ${ }^{13}$. A mais recente, de John Jairo Gómez Montoya, de $2012^{14}$, tem sido realizada a partir da versão francesa de Lamy/Nouss (cfr. infra), a qual, hoje em dia, pode ser considerada modélica em relação a muitos aspetos.

Um ano depois da tradução de Murena, publica-se a primeira versão inglesa, das três que existem neste momento. Esta versão, de Harry Zohn, que viveu já três reedições desde 1968, com as respetivas revisões e comentários ${ }^{15}$, acabou por ser aquela que ia dominar a receção da "Tarefa" no mundo anglófono até aos anos noventa, embora se tenha revelado deficiente em termos de qualidade. A segunda versão inglesa, realizada por James Hynd e E. M. Valk também saiu em 1968 (reeditada em 2006) ${ }^{16}$, mas sem nunca ter alcançado um público tão vasto como a tradução de Zohn. Hoje em dia, a versão inglesa que deve ser considerada de referência é a de Steven Rendall, publicada em 1997 (reeditada em 2012) ${ }^{17}$. A história das traduções e receções da "Tarefa" no espaço anglófono sempre

\footnotetext{
11 "La tarea del traductor", em Teorías de la traducción: antología de textos, ed. por Dámaso López García, Cuenca: Ediciones de la Universidad de Castilla-La Mancha 1996, 335-347. 12 "La tarea del traductor", em Francisco Lafarga (ed.): El discurso sobre la traducción en la historia. Antología bilingüe. Barcelona: EUB, 1996, p. 448-470.

13 "La tarea del traductor", em Walter Benjamin: Obras, vol. IV:1, Madrid: Abada 2010, 9-22.

14 "El abandono del traductor" (a partir da tradução de Nouss/Lamy), em Mutatis Mutandis, v. 5 , n. 1. 2012. p. 132-163.

15 "The Task of the Translator", em Walter Benjamin: Illuminations. Essays and Reflections. New York: Harcourt, Brace \& World 1968, 69-82; Walter Benjamin: Selected Writings, vol. I, 1913-1926, ed. por Marcus Bullock e Michael W. Jennings, London/Cambridge: Harvard University Press 1996, 253-263 (versão revisada pelo autor); Lawrence Venuti (ed.): The Translation Studies Reader, London / New York: Routledge 2000, 15-25 (inclui “A note on Harry Zohn's Translation" de Steven Rendall).

16 “The Task of the Translator", em Delos 2, 1968, 76-99 e em D. Weissbart / Astradur Eysteinsson (eds.): Translation - Theory and Practice. A Historical Reader, Oxford/New York: Oxford University Press 2006, 298-307.

17 "The Translator's Task", em TTR- Traduction, Terminologie, Rédaction, vol. X, $\mathrm{n}^{\circ}$ 2, 1997, 151-165, < http://www.erudit.org/revue/ttr/1997/v10/n2/index.html > (acesso 12/03/2017) e em Lawrence Venuti (ed.): The Translation Studies Reader, Third Edition, New York: Routledge 2012, 75-83.
} 
fora acompanhada por numerosos debates, estudos e comentários, protagonizados por Paul de Man, Carol Jacobs, Harry Zohn, Steven Rendall, Lawrence Venuti, Douglas Robinson, entre outros.

No âmbito francês também se realizaram até agora, no mínimo, três traduções: A primeira surge em 1971, da autoria de Maurice de Gandillac (reeditada em 2000) ${ }^{18}$; a segunda foi realizada por Martine Broda em $1991^{19}$ e a terceira, a mais intensamente trabalhada e documentada de todas, resultou de uma colaboração entre Laurent Lamy e Alexis Nouss, de $1997^{20}$. A receção filosófica e teórica da "Tarefa" tem sido especialmente fecunda na França, com destaque para os nomes de Jacques Derrida, Paul Ricoeur, Antoine Berman, Alexis Nouss, entre muitos outros.

A enorme atração exercida por este ensaio, também ficou demonstrada pelas três traduções que se realizaram ao catalão, embora entretanto já possam existir mais versões. A pioneira tem sido a versão de Antoni Pous, de 1983 (reeditada já em 1984) ${ }^{21}$ e revisada por Pilar Estelrich no ano $2000^{22}$, mas também uma tradução ainda inédita de Marc Jiménez Buzzi, de 2010. Em 2007, publicou-se uma versão galega, realizada por Burghard Baltrusch, Silvia Montero Küpper e Xoán Manuel Garrido Vilariño ${ }^{23}$.

No entanto, o âmbito mais surpreendente é o da língua portuguesa, onde já existem pelo menos dez versões da "Tarefa". No caso do português europeu, a tradução de João Barrento foi publicada primeira em 2008, no Brasil, tendo sido revisada na sua recente edição das obras completas de Benjamin em 2015. Em 2009,

18 "La tâche du traducteur", em Walter Benjamin: I. Mythe et violence, Évreux: Denoël 1971, 261-275 e em Walter Benjamin: Oeuvres I, Paris: Gallimard 2000, p. 244-262.

19 "La tâche du traducteur", em PO\&SIE 55, 1991, p. 150-158.

20 "L'abandon du traducteur", em TTR-Traduction, Terminologie, Rédaction, vol. X, $\mathrm{n}^{\circ} 2$, 1997, 13-69, disponível em < http://www.erudit.org/revue/ttr/1997/v10/n2/index.html > (acesso 12/03/2017).

21 “La tasca del traductor”, em Reduccions, Vic, 19, 1983, p. 47-58 e em Manuel Carbonell (ed.): Art i literatura. Vic: Eumo 1984.

22 "La tasca del traductor", em Enric Gallén et al.: L'art de traduir. Reflexions sobre la traducció al llarg de la història, Vic: Eumo 2000, p. 338-361.

23 "O cometido de quen traduce", em Viceversa: revista galega de tradución, Vigo: ATG, 13, 2007, 79-103, disponível em < http://webs.uvigo.es/webatg/viceversa/num13.htm> (acesso 12/03/2017). 
surgiu outra versão, da filósofa Maria Filomena Molder ${ }^{24}$, junto com outra minha, ainda inédita ${ }^{25}$.

Mas é a história da tradução e receção da "Tarefa" no Brasil que resulta especialmente ampla e que mereceria um estudo específico, do qual só poderei oferecer aqui alguns apontamentos que poderão demonstrar como a natureza deste texto foi pedindo constantes retraduções e debates. Os inícios da receção no Brasil poderiam ser situados no âmbito de um estudo sobre a versão da Antígona de Bertolt Brecht (1948), comentado por Haroldo de Campos em “A palavra vermelha de Hölderlin” (1967). Desde os anos 60 começa, assim, o que irá ser a grande vaga de receção da obra benjaminiana no Brasil até aos nossos dias. O texto completo da "Tarefa", mas também fragmentos soltos serão traduzidos e retraduzidos constantemente desde os anos 70 (por Haroldo de Campos, Márcio Seligmann-Silva, Susana Kampff Lages, entre muitos outros). A primeira tradução ao português do Brasil é de Fernando Camacho, de 1979 (reeditada em 2008) ${ }^{26}$ e, entre 1991 e 1994, realiza-se uma segunda tradução, esta vez por uma equipa dirigida por Karlheinz Barck $^{27}$, a qual será revisada, em 1994, por Johannes Kretschmer (reeditada em 2008) ${ }^{28}$. Em 2001, Susana Kampff Lages inicia uma

${ }_{24}$ “A Tarefa do Tradutor”, disponível em < http://www.c-e-m.org/wp-content/uploads/atarefa-do-tradutor.pdf $>$ (acesso 12/03/2017).

25 "A tarefa-abandono de quem traduz", disponível em < https://uvigo.academia.edu/Burghard Baltrusch/Drafts $>$ (acesso 17/03/2017).

26 "A tarefa do tradutor", em Humboldt, 40, 1979, 38-45 e em Lucia Castello Branco (Hg.): A tarefa do tradutor de Walter Benjamin: quatro traduções para o português, Belo Horizonte: Faculdade de Letras/Universidade de Minas Gerais 2008, 25-49, disponível em $<$ http://www.letras.ufmg.br/vivavoz/data1/arquivos/atarefadotradutor-site.pdf > (acesso 12/03/2017).

${ }^{27}$ Com Dirce Riedel, Ivo Barbieri, Luiz Costa Lima, Cristina Ferraz, Sônia Barbosa, Vera Lins, Adauri Bastos, Anna Lúcia de Oliveira, Gustavo Krause, Heloísa Rocha, Idemburgo Félix, João Cezar de Castro Rocha, Lara V. da Costa, Luciana Muniz, Tânia Dias, Thereza Vianna e Valéria Vale, “A Tarefa do Tradutor”, in Cadernos do Mestrado/Literatura, 1991, Rio de Janeiro: Edições UERJ.

28 "A Tarefa do Tradutor", em Cadernos do Mestrado/Literatura, 1994, 5-32 Rio de Janeiro: Edições UERJ e em Lucia Castello Branco (org.): A tarefa do tradutor de Walter Benjamin: quatro traduções para o português, Belo Horizonte: Faculdade de Letras/Universidade de Minas Gerais 2008, 51-65, disponível em < http://www.letras.ufmg.br/vivavoz/data1/ arquivos/atarefadotradutor-site.pdf $>$ (acesso 12/03/2017).

Cad. Trad., Florianópolis, v. 38, $\mathrm{n}^{0}$ 2, p. 32-60, mai-ago, 2018 
sucessão de retraduções com o título "A Tarefa-Renúncia do Tradutor", da qual se conhecem, até ao momento, três versões ${ }^{29}$.

Em paralelo, decorreu no Brasil uma diversificada e complexa receção geral da obra de Walter Benjamin no contexto da cultura brasileira erudita da segunda metade do século XX. No âmbito artístico, este processo começa com o concretismo dos anos 50 (Décio Pignatari, Haroldo de Campos, Augusto de Campos, etc.) quando se começou a sentir a necessidade de adaptar a nova realidade brasileira, criada pela segunda revolução industrial, à arte e à literatura. Haroldo de Campos chegou a comparar a poesia concreta com a pensée sauvage de Lévi-Strauss, como uma "lógica da analogia ou do analógico" (1977, p. 70), através da qual a poesia se podia aproximar da estrutura real das coisas, notando-se já aqui certa influência da "Tarefa". Mas a receção de Benjamin no Brasil relaciona-se, também, com o contexto da ideia sócio- e filosófico-cultural da antropofagia, que parte dos primeiros cronistas do século XVI (Staden, Jesuiten), sendo depois desenvolvida pelos românticos e, muito especialmente, pelos modernistas, vivendo uma continuação através do concretismo e do tropicalismo até à atualidade. Mas é, sobretudo, através dos principais ensaios e textos teóricos que publica Haroldo de Campos entre 1963 e $1997^{30}$ que a noção cultural e filosófica da antropofagia ficará associada à receção da "Tarefa". Nestes ensaios, o poeta e teórico paulista foi adaptando as ideias benjaminianas a uma perspetiva nitidamente brasileira, tentando até superá-las, ao criar uma linguagem que pretendia ser, simultaneamente, icónica, transparente e concreta.

\footnotetext{
${ }^{29}$ Em Werner Heidermann (ed.): Clássicos da Teoria da Tradução - Antologia Bilíngüe, vol. I, Florianápolis: Universidade Federal de Santa Catarina / Núcleo de Tradução 2001, 189-215; em Lucia Castello Branco (ed.): A tarefa do tradutor de Walter Benjamin: quatro traduções para o português, Belo Horizonte: Faculdade de Letras / Universidade de Minas Gerais 2008, 66-81, disponível em < http://www.letras.ufmg.br/vivavoz/data1/arquivos/ atarefadotradutor-site.pdf $>$ (acesso 12/03/2017) e uma versão inédita.

30 "Da tradução como criação e crítica” (1963), “A poética da tradução" (1977), “A palavra vermelha Hölderlin" (1977), Deus e o Diabo no Fausto de Goethe (1981), "Para além do princípio da saudade. A teoria benjaminiana da tradução" (1984), "Da transcriação: poética e semiótica da operação tradutora" (1987) e "A língua pura na teoria da tradução de Walter Benjamin" (1997).
} 
Este esboço muito rudimentar de um panorama das inúmeras traduções e versões de traduções da "Tarefa" surgidas nos últimos cinquenta anos, e ao qual faltaria por acrescentar as histórias de receção em muitas outras línguas e âmbitos culturais, ainda assim já evidencia como este ensaio foi colocando os mais diversos problemas de tradutibilidade e de intradutibilidade. O Vocabulaire européen des philosophies, editado por Barbara Cassin, indica como exemplo de intradutibilidade um texto “ce qu'on ne cesse pas de (ne pas) traduire" (2004, p. XVII), uma definição da qual a "Tarefa" poderia ser um dos exemplos por excelência.

Tentarei aproximar-me desta circunstância através de uma das passagens da "Tarefa" que mais problemas de tradução têm levantado e que, até na língua de partida, resulta ser uma das mais misteriosas e hermeneuticamente complexas. É precisamente nesta passagem que Benjamin justifica a sua teoria de uma tradutibilidade geral e absoluta de todas as formas linguísticas com a necessidade de adotarmos uma perspetiva não antropocêntrica:

[...] deve ser assinalado que certos conceitos de relação conservam o seu bom sentido e, talvez, até mesmo o seu melhor sentido, quando não são referidos, exclusivamente e desde o princípio, ao ser humano. Seria lícito falar de uma vida ou de um instante inesquecíveis, mesmo que todos os seres humanos os tivessem esquecido. Pois se a sua natureza exigisse não serem esquecidos, aquele predicado não incluiria nada de falso, mas apenas uma exigência a que os seres humanos não correspondem mas também a referência a um domínio, no qual essa exigência fosse correspondida qual comemoração à-Deus (Gedenken Gottes). Por conseguinte, a tradutibilidade de configurações linguísticas (Sprachgebilde) requer que seja considerada, mesmo que fossem intraduzíveis para os seres humanos. E, em certa medida, não o deveriam ser, se partirmos de um conceito de tradução rigoroso? - É a partir de uma tal desvinculação que deve ser colocada a questão se a tradução de determinadas configurações linguísticas deve ser exigida. Pois vale o 
princípio: se a tradução é uma forma, a traduzibilidade tem de ser parte fundamental de certas obras.

A tradutibilidade é inerente à natureza de certas obras; [...]. (BENJAMIN, IV:1, p. 10, trad. minha)

Na tradução francesa de Lamy/Nouss, os autores dedicam uma nota final de uma página inteira a uma extensa explicação da sua opção de taduzir o conceito alemão "auf ein Gedenken Gottes” com "un à-Dieu” (1997, p. 35-36). Tanto a versão galega (Baltrusch, Montero e Garrido) como a minha versão portuguesa, mas também a versão castelhana de Gómez Montoya se deixaram influenciar, de formas ligeiramente diferentes, por esta argumentação. Podíamos dizer que as questões que coloca a tradução desta expressão estão diretamente relacionadas com os aspetos do in/traduzível e da in/ tradutibilidade.

De uma forma geral, o antagonismo traduzível/intraduzível forma deriva-se da base binária da hermenêutica ocidental, dominada por dualidades tipo significado-significante (Saussure), inconsciente-consciente (Freud) ou consciência-conteúdo (Husserl). Arturo Leyte (2013) fala de duas formas de interpretação dos trânsitos que habitualmente acontecem neste tipo de lógica binária, o que irei adaptar às questões de tradutibilidade e intradutibilidade em Walter Benjamin. Uma forma de interpretar os trânsitos entre os binários seria a de uma "hermenêutica como teoria geral da interpretação", que parte da ideia de uma tradutibilidade geral, enquanto a outra perspetiva centrar-se-ia numa hermenêutica da intradutibilidade, a partir da qual "o próprio trânsito acaba por ser algo inacessível, [ou] inexponível” (LEYTE, 2013, p. 225). Podíamos agora relacionar a primeira forma, que corresponde a uma teoria geral de interpretação, com aquilo que Benjamin considera ser o traduzível, inerente a certas obras literárias, sugerindo que esta noção até podia ser extensiva aos fenómenos em geral. A segunda perspetiva, aquilo que se considera fundamentalmente inacessível e inexponível, relacionar-se-ia com a noção de intradutibilidade, à qual também se alude na "Tarefa”, ainda que não se concretize demasiado. 
No trecho em questão, Benjamin emprega a já referida locução "auf ein Gedenken Gottes" que traduzo para português com "qual comemoração à-Deus". Não pretendo discutir aqui em detalhe tudo o que me levou a transpo-la desta forma, mas gostava de contextualizar brevemente a minha interpretação da locução que, em alemão, pode referir-se diretamente à comemoração de Deus ou ao modo no qual esta comemoração é feita. Porém, penso que se podia relacionar esta fórmula com a ideia e prática da comemoração na liturgia judaica, na qual se procura transcender a noção de uma simples comemoração humana. Antes, o culto judaico pretende convocar a presença e ação do próprio Deus (cf. EBENBAUER, 2016; WAHLE, 2006), ou seja, de uma esfera que excede a condição humana. Também no sufismo existe a noção de um tipo de comemoração (dhikr) que pretende tornar presente o próprio Deus para, de certa forma, sublimar o humano.

Ainda que a linguagem bíblica, que Benjamin costumava empregar com certa frequência, pudesse estar a sugeri-lo, não devemos cair na tentação de uma interpretação teológica desta passagem da "Tarefa". Como filósofo e crítico escéptico da linguagem que era, é bastante mais provável que Benjamin se tenha aproveitado do potencial retórico da terminologia bíblica para evocar, de uma forma estilisticamente mais eficaz, a meta utópica (inalcançável, mas necessária) da "pura língua" e o preceito de que "a tradução é uma forma". Se a expressão "Gedenken Gottes" aludisse a uma superação da condição humana, também a ideia da "pura língua” seria, em última instância, uma forma de se referir a uma hipotética identidade de significado e significante, na qual ambos os elementos se neutralizam ou anulam mutuamente. O que as expressões reine Sprache ou Gedenken Gottes têm de aparência essencialista talvez não seja mais do que uma estratégia não antropocêntrica, cujo significado podia ser resumido com a seguinte fórmula: A tradutibilidade geral é inerente à natureza precisamente porque não depende do ser humano.

É óbvio que para o ser humano existem fenómenos intraduzíveis, mas esta circunstância não afeta à tradutibilidade geral dos 
fenómenos porque, segundo Benjamin, o traduzível é uma função independente da condição humana. Assim, haveria ainda outra síntese explicativa e complementária do trecho em questão: $A$ intradutibilidade designaria aquilo que excede a nossa capacidade de conhecimento e entendimento forçosamente antropocêntricos, aquilo que nos aparece como inacessível, inexplorável ou inexponível.

Regressando à distinção proposta por Leyte, entre uma hermenêutica com minúscula e outra com maiúscula, poderíamos construir o hipotético enunciado Isto é traduzível (no sentido de $\mathrm{S}=$ P), a ser empregado num contexto dado para identificarmos uma qualquer noção de tradutibilidade. Aqui, o vínculo entre os dois elementos ( $\mathrm{S}=$ isto e $\mathrm{P}=$ traduzível) caracterizar-se-ia por "uma ambiguidade estrutural, radicalmente assimética" (LEYTE, 2013, p. 228). O vínculo que os une aponta, simultaneamente, para os dois lados embora às diferenças fundamentais impossibilitem uma identificação ${ }^{31}$. Seria como se disséssemos que não se deve confundir o fenómeno traduzível com o seu significado. O determinante isto tem a função de designar o fenómeno que se considera traduzível, portador de tradutibilidade. Já representa uma parte substancial do próprio trânsito, do processo de tradução daquilo que se considera a coisa, o real, para a norma, a convenção linguística ou discursiva. No entanto, o que foi designado por isto, o fenómeno traduzível em si mesmo, trata de aparecer nesta tradução, mas nunca consegue fazê-lo completamente. O fenómeno, supostamente original e traduzível, habitualmente partilha com a sua tradução algum tipo de linguagem (seja esta verbal, visual, material, etc.), a qual é, já em si mesma, o resultado de um trânsito.

Se voltarmos agora à "Tarefa" de Benjamin, inserida no contexto de uma tradução poética, poderíamos estabelecer, até, uma comparação com a forma na que Heidegger relacionou linguagem e poesia:

\footnotetext{
31 "[U]na ambigüedad estructural, radicalmente asimétrica. Va en dos direcciones: la que remite a $\mathrm{S}$ y la que remite a $\mathrm{P}$, y ambos lados son tan diferentes que, de ese modo, se impide la identidad. En realidad, "S es P" es un enunciado estructuralmente falso, porque S nunca es P." (LEYTE, 2013, p. 228).
} 
A própria linguagem é composição em sentido essencial. Como a linguagem é aquele acontecimento no qual a cada vez o ente se descerra como ente para os humanos, por isso a poesia, a composição no sentido mais estrito, é a mais originária composição em sentido essencial. A linguagem não é composição por ser a poesia primordial [Urpoesie], mas sim, a poesia sucede a si mesma [ereignet sich] na linguagem porque esta resguarda [verwahrt] a essência originária da composição. (2007, p. 55-56)

A noção heideggeriana de uma "mais originária composição em sentido essencial" guarda uma relação com a já mencionada inexponibilidade do tránsito que identifiquei, pela sua vez, com a intradutibilidade. Mas também sugere uma possível leitura transversal a partir da filosofia da tradução de Benjamin e do seu conceito da pura língua. $\mathrm{Na}$ "Tarefa", Benjamin entende a "pura língua" como uma constante da tradutibilidade, ou seja, a capacidade do original para se adaptar a outros contextos e para projetar a sua tradução através dos tempos:

\begin{abstract}
Nessa pura língua - que nada mais tem em mente e que nada mais expressa, mas que representa, enquanto palavra inexpressiva e criadora, o tido em mente em todas as línguas - toda comunicação, todo significado e toda intenção chegam finalmente a um estrato, no qual estão destinados a desvanecerem. E justamente a partir desse estrato, a liberdade da tradução ratifica-se em termos de um direito novo e superior. (BENJAMIN, IV:1, p. 19, trad. minha)
\end{abstract}

Este último estrato seria a conditio sine qua non de todo o processo tradutivo - e também do processo poético se quiséssemos compará-lo com a linguagem em termos de uma composição primordial ou essencial. A sua relação com a noção de intradutibilidade não precisa ter um contexto metafísico ou fundacional ( $c f r$. 
CAMPOS, 1997), se a relacionarmos com aquilo que, simples e naturalmente, excede a nossa condição antropocêntrica.

Benjamin diz que neste estrato profundo desvanece "todo significado e toda intenção". Lamy/Nouss e Montoya apoiaram-se nesta passagem quando optaram por traduzir "Aufgabe" exclusivamente com "abandono", uma decisão com a qual pessoalmente não concordo. A própria palavra alemã "Aufgabe" tem os dois significados e Benjamin aproveita esta condição para expor que é precisamente a dupla vinculação com o traduzível e o intraduzível o que abre entre os dois extremos um terceiro espaço intermédio. Este espaço in-between (BHABBHA, 1994) é o que garante a liberdade da ação tradutiva. Há uma noção de abandono, mas continua a haver também uma tarefa clara, um paradoxo sem solução que é preciso aguentar. Uma vez que esta duplicidade não se deixa reproduzir em nenhuma outra língua, a tradutora e crítica Susana Kampff Lages optou, na sua primeira tradução ao português do Brasil, pelo composto "tarefa-renúncia", sendo esta versão, por enquanto, a única públicada que destaca este double bind fundamental no próprio título.

A tridimensionalidade do traduzível, intraduzível e do espaço intermédio entre estes também afeta a própria ideia de haver um original. A noção do original implica a existência de uma dimensão distinta à língua ou cultura de partida, enquanto o trânsito-tradução para outra língua ou cultura pressupõe mudanças que não têm lugar em nenhuma das línguas ou culturas em questão, mas sim no espaço entre elas. Cada trânsito-tradução torna a situação mais complexa e aumenta o seu caráter babélico, tal como o veio ilustrando a referida sucessão de traduções e versões que viveu a "Tarefa" ao longo das últimas quatro décadas.

Assim, em toda a tradução o trânsito real e verdadeiro é aquele que não tem volta atrás, porque com cada avanço alguma coisa mudou (LEYTE, 2013, p. 229) - seja em relação à língua, ao significado ou aos seus contextos sincrónico e diacrónico. Sempre existirá um elemento que é o fenómeno traduzível no seu preciso momento sincrónico, e que desencadeia, mas também limita o 
trânsito-tradução, uma vez que resulta ser irrepetível e porque a tradução está, naturalmente, sujeita às contingências de uma espacio-temporalidade, tanto no momento da produção como no da receção.

Se interpretássemos o trânsito-tradução de maneira exclusivamente diacrónica, só veríamos o seu valor lógico-gramatical. Mas na passagem da coisa ao seu predicado, a ambiguidade do trânsito já fica evidente, tal como o ilustra a já mencionada e hipotética proposição Isto é traduzível, onde o é acaba por ter uma condição bidirecional. Esta bidirecionalidade evita que se possa produzir uma identificação nem com um lado nem com o outro. O momento do trânsito fica marcado por uma noção de diferença que instala a tradução, num espaço in-between (cfr. BHABHA, 1994). Retomando a Heidegger, a perspetiva hermenêutica requer, sobretudo, uma perspetiva sincrónica, uma vez que o trânsito é um movimento irreversível. O traduzível visto como acontecimento define-se através de um presente, traduzível, mas logo também tão irrepetível como o acontecimento passado do suposto original, que nunca poderá reaparecer completamente.

O traduzível tem lugar, primordialmente, no contexto da prática e da receção sincrónicas, enquanto o intraduzível aponta para o âmbito da teorização do excluído e do inexplorável no seu respetivo presente histórico. Segundo Benjamin, as obras de arte seriam testemunhas da filosofia da história, mas também expressões das inclinações metafísicas, políticas ou económicas da sua época (VI:1, 117, 219). As múltiples traduções da "Tarefa", as suas tentativas de traduzir a tradição e a sua oposição às estruturas canonizadoras, representam um desejo de resignificar "o original" e "o real". Exploram este espaço in-between, esta possibilidade transfiguradora e inovadora que lhes oferece o continuum das traduções para encenarem as suas diferenças culturais, linguísticas e epistemológicas. Mas também para colocarem o problema geral da representação que têm em comum, e o que Benjamin caracterizou como: 
[a]quela relação pensada e intimíssima entre as línguas [que] constitui, porém, uma convergência peculiar. Esta consiste no facto de as línguas não serem alheias umas às outras, mas sim, a priori e abstraindo de todas as relações históricas, afins naquilo que pretendem dizer. (BENJAMIN, IV:1, p. 12) $)^{32}$

Lembremos que Benjamin desvinculou a dimensão do traduzível do humano como único valor central e fundacional. É precisamente esta noção não antropocêntrica da tradutibilidade que permite ver no traduzível também uma função de eco longínquo daqueles aspetos inacessíveis, inexploráveis ou inexponíveis e que só sobrevivem nas incessantes transformações de uma tradução entendida como devir ontológico (Deleuze), como um vir-a-ser já sendo.

Esta noção já se encontrava na base da argumentação do ensaio "Sobre a linguagem em geral" de 1916, onde Benjamin relacionava o processo tradutivo com a preocupação principal da filosofia continuando, assim, o caminho esboçado pelos românticos. Neste texto, Benjamin situa, de uma forma sistemática, a tradução como uma função originária da evolução linguística, como

[...] a tradução da linguagem das coisas para a linguagem humana. É preciso justificar o conceito da tradução como estrato mais profundo da teoria da linguagem [...] A traducibilidade de umas línguas para outras é dada pela já mencionada relação das línguas como médios de densidade distinta. A tradução é a transposição de uma língua para a outra através de um continuum de transformações. Continua de transformações, e não os confins abstratos da igualdade e semelhança, atravessam a tradução. (BENJAMIN, II:1, p. 151, trad. minha)

Neste sentido, a tradução parte das coisas, da própria natureza, cuja linguagem precisa de ser traduzida à "linguagem humana". A

${ }^{32}$ Cfr. também Bhabha, 1994, p. 227. 
este amplíssimo conceito de tradução junta-se um conceito igualmente amplo de língua. Quando Benjamin fala de uma continuação da "transposição de uma língua a outra através de um continuum de transformações", as quais não poderão ser compreendidas pelos "confins abstratos da igualdade e semelhança", ou seja, com equivalências formalizadas por uma lógica qualquer, oferece-nos uma definição da tradução como dinâmica universal. O acontecimento da tradução seria, assim, a apreensão e interpretação do real. A língua e os seus derivados sistémicos (como a a teoria da linguagem) só entram em existência quando recebem, através de um processo tradutivo, elementos alheios (culturais, ideológicos, etc.). Numa apresentação da revista Angelus Novus, de 1921, Benjamin escreve: "De facto, as traduções [...] não devem ser entendidas como transmissão de modelos, como tinha vindo a ser tradição, mas como aprendizagem insubstituível e rigorosa do próprio devir da língua" (p. 241, trad. minha). Esta desconstrução da língua como mathesis universalis é característica da filosofia da linguagem que Benjamin desenvolveu depois da $1^{\text {a }}$ Guerra Mundial, uma atitude pessimista que também o levou a se afastar do ativismo político.

Para Benjamin, a tradução e as condições de tradutibilidade e intradutibilidade acabam por ser um paradeigma, uma orientação para o pensamento sobre a língua e sobre os sistemas de signos em geral. Se a origem da língua for, já em si, um ato de tradução, nenhum acontecimento tradutivo poderá ser considerado secundário ou deduzido a posteriori, como se fosse uma imitação ou cópia:

A tradução transplanta, portanto, o original para um âmbito ao menos (ironicamente) mais definitivo da língua, na medida em que já não poderá ser transferido dali para parte alguma por nenhuma translação; mas para dentro desse âmbito da língua só poderá ir sendo elevado, começando sempre de novo e em outras partes. Não é em vão que a palavra "ironicamente" lembrará o pensamento do romantismo. (BENJAMIN, IV:1, p. 15, trad. minha) 
Esta condição, tão irónica como ao mesmo tempo trágica, de um original sujeito a um recomeço eterno, acaba por lhe retirar a sua exclusividade, sugerindo que também o original é o resultado de uma tradução. É deste facto de o próprio original estar sujeito ao devir das línguas que Benjamin deduziu a sua constante da tradutibilidade, que acaba por ser também, e de forma inseparável, uma constante de intradutibilidade.

Haroldo de Campos, quem fora um dos melhores conhecedores da obra benjaminiana, viu nas suas ideias uma "grande saudade" e uma "nostalgia da reconciliação na totalidade e homogeneidade do ser” (1984, p. 8), mas também da aura, o que seria, afinal, um resquício do romântico. Campos deduziu disso a necessidade de abandonarmos à "metafísica benjaminiana do traduzir, para convertê-la numa física, [...], liberada do horizonte teológico da "língua pura", porque era preciso "[c]ompreender a história como pluralidade sufocada e a historiografia como instância de rutura e possibilidade de tradução transgressora" (1984, p. 8).

Porém, penso que é perfeitamente possível obviar este "horizonte teológico" se encararmos a "pura língua" como um essencialismo estratégico, indispensável para integrar a noção da intradutibilidade no traduzível. Este processo contém, até, uma potencialidade transgressora, uma vez que é motivado pelo desejo de libertar a língua da ditadura do sentido normativo, precisamente através do acontecimento tradutivo. Assim, a "história como pluralidade" e a historiografia como "rutura e possibilidade de tradução transgressora" já formariam parte das noções de temporalidade e de historicidade benjaminianas, tanto na "Tarefa" como na sua perspetiva tradutológica em geral.

Um exemplo seria a alegorese interlinear que Benjamin adscreve, na "Tarefa", às traduções que Hölderlin realizou do grego: "Nelas, a harmonia das línguas é tão profunda que o sentido só é tangido pela língua como uma harpa eólica pelo vento" (1923, IV:1, p. 23, trad. minha). Não se trata de uma harmonia do sentido, mas de uma harmonia que surge a partir de um paulatino abandono do próprio sentido e da consequente aceitação de espaços 
de intradutibilidade. A expressão "fugaz" (al. flüchtig) indica a precariedade das equivalências semánticas entre as línguas e confere mais importância ao movimento, à evolução da(s) língua(s) e à complementação dos diferentes "modos de ter em mente". É precisamente nesta transição entre os "modos de ter em mente" das línguas que se negoceiam os elementos traduzíveis e intraduzíveis. $\mathrm{Na}$ "Tarefa", Benjamin emprega o exemplo do pão, cujas formas e sabor variam de cultura a cultura embora as palavras sugiram uma equivalência absoluta. No trânsito-tradução entre os "modos de ter em mente", neste terceiro espaço criativo e ao mesmo tempo transgressor que se abre entre eles, o intraduzível acaba por forçar uma espécie de imobilização fragmentária:

Assim como os cacos de um vaso, para poderem ser recompostos, precisam adaptar-se nos mais mínimos detalhes, mas sem exatidão absoluta, a tradução deve, em vez de se assemelhar ao sentido do original, ir-se amoldando, na própria língua, amorosamente e chegando até aos pormenores, ao modo de ter em mente do original, fazendo assim com que ambos sejam reconhecidos, tal como cacos enquanto fragmentos de um vaso, como fragmentos de uma língua maior. (BENJAMIN, IV:1, 1923, p. 18, trad. minha)

Os "modos de ter em mente" das línguas individuais são representados pelos fragmentos de uma "língua maior" que é, em última instância, este essencialismo estratégico da "pura língua" com a sua dupla vinculação ao traduzível e ao intraduzível. O que parece ser, à primeira vista, uma defesa de técnicas metonímicas, parte da formação verbal alemã "anbilden" (amoldar-se, lit. *comproduzir). Com a noção processual do verbo, Benjamin quis indicar a condição sempre fragmentária da língua e como esta impede a formação de um sentido fixo e estável, seja no caso do original seja no da tradução. A imagem do vaso recomposto a partir de cacos é a alegoria da "natureza essencial" do discurso estratégico da "pura língua", que não admite nenhuma simbologia da origem e convida 
à resistência ao próprio discurso essencialista que o conceito parece estar a propor. A sua utopia (inalcançável) é a recomposição dos "modos de ter em mente" de todas as línguas e a sua função é mostrar como cada tradução tem de realizar um movimento duplo e paradoxal: Por um lado, produz o fragmento de uma língua que já tinha surgido como fragmento a partir de uma tradução anterior; pelo outro, amolda-se com o seu caráter fragmentário a um novo "modo de ter em mente".

Ainda que houvesse um resquício de horizonte teológico em Benjamin, esta fragmentação da ideia do original já o invalidaria (o próprio Deus, como suposto original derradeiro, também seria a tradução de uma tradução). Assim, a "Tarefa" e "Sobre a linguagem" já preparam a teoria de tradução transgressora e descontrutivista de Haroldo de Campos, porque definem a tradução como o lugar onde transparecem tanto o original como a liberdade de deslocamentos e ruturas. É um terceiro espaço de transposição contínua, comparável aos espaços de transformação que Benjamin via nas passages do Paris de novecentos. Era uma impressão de dialética de estabilidade e inestabilidade, de um movimento alostático que procura estabilidade através de constantes mudanças, Assim, permite questionar noções fundacionais como objetividade e conhecimento e abre uma perspetiva tanto poética como poiética sobre a tradução. Como as passages, também a "pura língua" não permite ser fixada. É uma construção utópica que só aparece en passant numa prática tradutiva que amolda língua após língua numa contínua colagem de fragmentos. Apesar de todos os esforços artesãos, a desfragmentarização, à qual o seu suposto essencialismo aspira, nunca poderá ser completada. O que poderia haver de teológico nela, relativizar-se-ia pelo convite à resistência estética que igualmente contém: Amoldar verdades sem nunca admiti-las como meta-narrativas fundacionais.

Em conclusão, a "pura língua”, e a ideia de intradutibilidade que contém, representa uma utopia meta-narrativa, mas também uma ferramenta crítica: $\mathrm{O}$ que nela aparenta ser essencialista devia ser reinterpretada como um recurso discursivo que pretende referir-se ao 
não antropocêntrico, a um espaço onde a tradutibilidade é inerente à natureza e independente do discurso humano. Benjamin subverte a função comunicativa da língua - porque a entendia como um afastamento do real - com a estratégia discursiva da "pura língua" que designa o intraduzível, aquilo que excede a nossa capacidade de conhecimento e entendimento forçosamente antropocêntricos. A prática tradutiva que segue estas pautas nunca termina e acaba por ser uma constante negociação entre momentos de construção e de desconstrução, uma constante reavaliação crítica das noções de verdade e de progresso. A perspetiva do "tradutor luciferino" de Haroldo de Campos vai ainda além das conceções benjaminianas, mas também representa a sua imediata continuação: $\mathrm{O}$ "movimento infinito da diferença" (1984, p. 7), que o pensador brasileiro reclamara, apoiando-se em Derrida, já se encontra esboçado no "continuum de transformações" do devir das línguas, cuja origem e expressão é o acontecimento tradutivo. Mas também na "pura língua", vista como estratégia de negociação entre o traduzível e o intraduzível.

À perspetiva teosófica e otimista de Klimt, Benjamin talvez tivesse respondido, melancolicamente, com a imagem dos escombros que a História amontoa aos pés daquele anjo a voar de costas em direção ao futuro que pintou Paul Klee ${ }^{33}$. Benjamin foi um melancólico ( $c f r$. LAGES, 2002), mas também um vanguardista, teórico de uma utópica tradutibilidade geral como também de uma escatológica intradutibilidade. Este paradoxo, difícil de pensar e de aguentar, mas ao mesmo tempo salutar e realista, é em grande parte responsável pela vitalidade intemporal do seu pensamento.

\footnotetext{
33 "Existe um quadro de Klee que se intitula Angelus Novus. Representa-se aí um anjo que parece estar a preparar-se para se afastar de alguma coisa que está a fitar. Os seus olhos estão escancarados, a sua boca está aberta e as suas asas desfraldadas. Tal é o aspecto que deve ter o anjo da História. O seu rosto está voltado para o passado. Ali onde aparece uma cadeia de acontecimentos diante de nós, ele vê uma única catástrofe que não cessa de amontoar escombros sobre escombros, arremessando-os a seus pés. Ele quereria ficar, despertar os mortos e recompor o que ficou destroçado. Mas do Paraíso sopra uma tormenta que se enredou nas suas asas e que é tão forte que o anjo já não é capaz de fechá-las. Esta tormenta impele-o imparavelmente para o Futuro, ao qual volta as costas, enquanto diante dele se vão amontoando os escombros até ao céu. Aquilo que nós chamamos o Progresso é esta tormenta." (BENJAMIN, I:1, p. 697, trad. minha).
} 


\section{Referências}

BADIOU, Alain. Theoretical Writings. Edited and translated by Ray Brassier and Alberto Toscano. London: Continuum, 2004.

BALTRUSCH, Burghard. Translation as Aesthetic Resistance: Paratranslating Walter Benjamin, Cosmos and History: The Journal of Natural and Social Philosophy, v. 6, n. 2, p. 113-129, 2010.

BENJAMIN, Walter. Über die Sprache überhaupt und über die Sprache des Menschen. In: TIEDEMANN, R.; SCHWEPPENHÄUSER, H. (eds.). Gesammelte Schriften. Frankfurt/Main: Suhrkamp [1916] 1991. vol. II. p. 140157.

Die Aufgabe des Übersetzers. In: TIEDEMANN, R.; SCHWEPPENHÄUSER, H. (eds.). Gesammelte Schriften. Frankfurt/Main: Suhrkamp [1923] 1991. vol. IV:1. p. 9-21.

. Über den Begriff der Geschichte. In: TIEDEMANN, R.; SCHWEPPENHÄUSER, H. (eds.). Gesammelte Schriften. Frankfurt/Main: Suhrkamp 1991. vol. I:1. p. 691-706.

BHABHA, Homi K. The location of culture. London: Routledge, 1994.

CAMPOS, Haroldo de. A língua pura na teoría da tradução de Walter Benjamin. Revista USP, v. 33. p. 160-171, 1997.

CASSIN, Barbara. Vocabulaire européen des philosophies. Dictionnaire des intraduisibles. Paris: Le Seuil; Le Robert, 2004.

DERRIDA, Jacques. Des tours de Babel. In: . Psyché - inventions de l'autre. Paris: Galilée, 1987. p. 203-236.

. L'oreille de l'autre: otobiographies, transferts, traductions: Textes et debats avec Jacques Derrida. Ed. por C. Levésque y C. McDonald. Montreal: VLB, 1982. 
FELLINGER, Markus et All. Gustav Klimt im Belvedere - Vergangenheit und Gegenwart. In: HUSSLEIN-ARCO, Agnes; WEIDINGER, Alfred (eds.). Gustav Klimt - 150 Jahre. Viena: Belvedere, 2012. p. 31-280.

FLIEDL, Gottfried. Gustav Klimt 1862-1918. Die Welt in weiblicher Gestalt. Köln: Taschen, 1989.

GADAMER, Hans-Georg. Hermeneutik I. Wahrheit und Methode. Grundzüge einer philosophischen Hermeneutik. Tübingen: J. C. B. Mohr (Paul Siebeck), 1990.

HEIDEGGER, Martin. A Origem da Obra de Arte. Tradução, comentário e notas de Laura de Borba Moosburger. Dissertação de Mestrado. Curitiba: Universidade Federal do Paraná, 2007.

LAGES, Susana Kampff. Walter Benjamin. Tradução e Melancolia. São Paulo: EDUSP, 2002.

LEYTE, Arturo. ¿Hermenéutica del texto o hermenéutica de la cosa?. In: El paso imposible. Madrid: Plaza y Valdés, 2013. p. 221-233.

NOVALIS (i.e. Georg Philipp Friedrich von Hardenberg). Fragmente. Bruchstücke philosophischer Enzyklopädistik. Der poetische Philosoph und der philosophische Poet. Ed. por Ernst Kamnitzer. Dresden: Jess Verlag 1929. Disponível em: < http://gutenberg.spiegel.de/buch/fragmente-6618/5 > . Acesso em: 11 mar. 2017.

SPIVAK, Gayatri Chakravorty. Subaltern Studies: Deconstructing Historiography. In: . In Other Worlds: Essays in Cultural Politics. New York: Methuen, 1987. p. 197-221.

Recebido em: 02 de novembro de 2017 Aceito em: 26 de fevereiro de 2018 Publicado em: maio de 2018

Burghard Baltrusch. E-mail: burg@uvigo.es 